\title{
WORKSHOP PENERAPAN MODEL PEMBELAJARAN PAKEM DI SMP PGRI I SAMBOJA KABUPATEN KUTAI KARTANEGARA
}

\author{
Nur Agus Salim ${ }^{1}$ \\ Fakultas Keguruan dan Ilmu Pendidikan \\ Email: nuragussalim@uwgm.ac.id
}

\begin{abstract}
ABSTRAK
Tujuan dalam kegiatan ini adalah peserta workshop mendapat tambahan wawasan ilmu pengetahuan tentang model pembelajaran aktif, kreatif, efektif dan menyenangkan dan Peserta workshop dapat menerapkan model pembelajaran aktif, kreatif, efektif dan menyenangkan dalam kegiatan belajar mengajar di kelas. Metode yang diterapkan dalam kegiatan ini adalah pemberian materi dan praktik langsung. Dalam workshop ini akan diberikan beberapa kegiatan yang meliputi penyajian materi, dan praktik beberapa metode pembelajaran aktif oleh peserta. Workshop ini memberikan beberapa materi yang terkait dengan upaya meningkatkan kualitas pembelajaran dengan pemberian materi tentang implementasi model pembelajaran aktif, kreatif, efektif dan menyenangkan.
\end{abstract}

Kata kunci: Model pembelajaran, Pakem

\section{PENDAHULUAN}

Pendidikan dipercaya sebagai alat strategis meningkatkan taraf hidup manusia. Melalui pendidikan manusia cerdas, memiliki skill, sikap hidup yang baik sehingga dapat bergaul dengan baik pula di masyarakat dan dapat menolong dirinya sendiri, keluarga dan masyarakat. Pendidikan menjadi investasi yang memberi keuntungan sosial dan pribadi yang menjadikan bangsa bermartabat dan menjadikan individunya menjadi manusia yang memiliki derajat.

Semakin baik pendidikan suatu bangsa, semakin baik pula kualitas bangsa itu, itulah asumsi secara umum terhadap program pendidikan suatu bangsa. Dengan demikian dapat dikatakan bahwa untuk meningkatkan kualitas bangsa ini maka harus meningkatkan kualitas pendidikannya.

Salah satu masalah yang dihadapi dunia pendidikan kita adalah masalah lemahnya proses pembelajaran. Dalam proses pembelajaran, anak kurang didorong untuk mengembangkan kemampuan berpikir. Proses pembelajaran di dalam kelas diarahkan kepada kemampuan anak untuk menghafal informasi, otak anak dipaksa untuk mengingat dan menimbun berbagai 
informasi tanpa dituntut untuk memahami informasi yang diingatnya itu untuk menghubungkannya dengan kehidupan sehari-hari. Akibatnya ketika anak didik lulus dari sekolah, mereka pintar secara teoritis, tetapi mereka miskin aplikasi.

Berdasar berbagai kondisi tersebut, kegiatan pelatihan ini sangat penting untuk diadakan. Workshop pembelajaran aktif, kreatif, efektif dan menyenangkan. Hal ini dapat menjadi bekal bagi guru agar dalam mengajar menjadi lebih aktif, kreatif, efektif, dan menyenangkan sehingga materi yang diajarkan oleg guru dapat diterima oleh siswa dengan mudah.

Sekolah yang menjadi sasaran kegiatan kali ini adalah SMP PGRI I Samboja Kab. Kutai Kartanegara. Disamping itu yang menjadi pertimbangan lain adalah pihak kepala SMP PGRI I Samboja Kab. Kutai Kartanegara telah mengajukan permohonan agar guru-guru di sekolah ini, dilatih untuk penerapan model pembelajaran aktif, kreatif, efektif dan menyenangkan (PAKEM). Adapun dengan pertimbangan tersebut maka workshop yang akan diadakan ini benar-benar sesuai dengan kebutuhan sekolah yang menjadi sasaran pengabdian.

\section{METODE}

Metode yang diterapkan dalam kegiatan ini adalah pemberian materi dan praktik langsung. Dalam workshop ini akan diberikan beberapa kegiatan yang meliputi penyajian materi, dan praktik beberapa metode pembelajaran aktif oleh peserta.

Adapun langkah yang akan ditempuh dalam kegiatan kali ini mencakup beberapa tahap berikut ini.

\section{Persiapan}

Tahap persiapan merupakan tahap awal sebelum pelaksanaan pengabdian masyarakat

Dalam tahap ini ada beberapa hal yang dilakukan:

a. Koordinasi Internal, dilakukan untuk merencanakan waktu pelaksanaan kegiatan

b. Penentuan peserta workshop 

c. Pembuatan modul workshop
d. Persiapan konsumsi, publikasi, lokasi, dokumentasi, dan lain-lain.

\section{Pelaksanaan Workshop}

Tahap ini merupakan tahap kegiatan workshop yang diberikan kepada para guru-guru yang ada di SMP PGRI I Samboja. Pelaksanaan pelatihan ini mencakup beberapa hal berikut.

\section{a. Penyajian Materi}

Materi yang disajikan terkait dengan perngenalan tentang model pembelajaran aktif, kreatif, efektif dan menyenangkan.

\section{b. Penugasan Praktik}

Pada akhir materi peserta dipandu secara langsung untuk praktik model pembelajaran PAKEM. Dalam hal ini Pemateri mendampingi, memandu dan mengarahkan peserta untuk praktik motode pembelajaran akttif.

\section{c. Refleksi dan Penutupan Program Pengabdian Masyarakat}

Pada bagian akhir kegiatan peserta melakukan refleksi hasil pelatihan. Para peserta diberikan evaluasi akan pelatihan ini. Dan dibuka sesi tanya jawab untuk memberikan pemecahan masalah kepada peserta dalam menyelesaikan berbagai masalah yang pernah dihadapinya

Setelah semua kegiatan yang telah direncanakan terlaksana, maka program ditutup dengan memberikan pesan kepada segenap peserta workshop untuk menerapkan apa yang telah didapatkan untuk memperbaiki pembelajaran.

\section{Evaluasi Kegiatan}

Evaluasi kegiatan ini dilakukan dengan beberapa cara. Evaluasi hasil dilihat dari tugas praktik para peserta yang ada.

\section{HASIL DAN PEMBAHASAN}

\section{A. Hasil Pelaksanaan Kegiatan Pengabdian Masyarakat}


Guru merupakan memiliki peran yang besar dalam proses pembelajaran. Guru harus selalu mengembangkan wawasannya agar tidak ketinggalan zaman. Apalagi kebutuhan siswa juga makin berkembang.

Pelatihan ini memberikan materi yang terkait dengan upaya guru dalam implementasi model pembelajaran aktif, kreatif, efektif dan menyenangkan (PAKEM) dan diberikan juga contoh langsung praktik beberapa metode pembelajaran aktif. Dalam kegiatan ini diharapkan agar pembelajaran yang diberikan oleh guru menjadi lebih atraktif sehingga meningkatkan minat dan kualitas belajar siswa. Materi yang disajikan oleh pengabdi dapat diterima, dicerna, dan dipahami peserta dengan baik.

Jumlah peserta yang sebanding dengan jumlah Pemateru yang berperan sebagai instruktur dan tutor menjadikan workshop ini menjadi lebih kondusif. Hal ini didukung pula dengan antusias para peserta dapat berkomunikasi aktif dengan pemateri dan dapat bekerjasama dengan baik dengan peserta lain.

Materi yang tersajikan mengenai implementasi model PAKEM serta beberapa metode pembelajaran aktif yang dapat diterapkan secara langsung dalam kegiatan pembelajaran di kelas.

Daftar materi dan pematerinya yang telah terlaksana dalam kegiatan ini antara lain :

Daftar Jenis Kegiatan, Materi, Pemateri, dan Waktu Pelaksanaan.

\begin{tabular}{|c|l|c|}
\hline Jenis & Pokok Bahasan (Materi) & \multicolumn{1}{c|}{ Pemateri } \\
\hline Teori & $\begin{array}{l}\text { Pengenalan tentang model pembelajaran } \\
\text { aktif, kreatif, efektif dan }\end{array}$ & Dr. Nur Agus Salim, M.Pd \\
&
\end{tabular}


Nur Agus Salim. JPKPM. Vol.1(1). 20-25. Juni 2021

\begin{tabular}{|c|l|l|}
\hline Pratik & Praktik metode pembelajaran aktif & Dr. Nur Agus Salim, M.Pd \\
& antara lain : & \\
a) Metode picture and picture & \\
& b) Metode number head together & \\
& c) Metode think pink and share & \\
\hline Evaluasi & Tanya Jawab & Dr. Nur Agus Salim, M.Pd \\
\hline
\end{tabular}

Para peserta dapat langsung berdiskusi dengan para pemateri secara langsung untuk memahami materi dan sharing pengalaman terkait dengan masalah yang tengah dihadapinya. Kegiatan ini dilaksanakan di salah satu ruang kelas SMP PGRI I Samboja yang cukup representatif. Kegiatan ini dihadiri 10 peserta dari guru-guru SMP PGRI I Samboja.

\section{KESIMPULAN}

Berdasarkan hasil pelaksanaan kegiatan pengabdian kepada masyarakat ini dapat disimpulkan beberapa hal sebagai berikut:

1. Workshop ini memberikan beberapa materi yang terkait dengan upaya meningkatkan kualitas pembelajaran dengan pemberian materi tentang implementasi model pembelajaran aktif, kreatif, efektif dan menyenangkan

2. Materi yang disajikan dapat diterima, dicerna, dan dipahami peserta dengan baik.

3. Workshop berlangsung lancar, tepat waktu dan sesuai dengan yang diharapkan dan para peserta dapat berkomunikasi dengan pemateri an bekerjasama dengan peserta lain dengan baik.

\section{DAFTAR PUSTAKA}

Budimansyah, Dasim, Suparlan \& Meirawan Danny. PAKEM, Pembelajaran Aktif, Kreatif, Efektif Dan Menyenagkan, Bandung: PT Genesindo, 2009.

Engkoswara \& Komariah. Administrasi Pendidikan.Bandung: Alfabeta ,2010.

Gora,Winastawan \& Sunarto, PAKEMATIK Strategi Pembelajaran Inovatif Berbasis TIK. Jakarta : Kompas Gramedia, 2010. 
Khoiru Ahmadi, Lif \& Amri, Sofan. PAIKEM GEMBROT, Mengembangkan Pembelajaran Aktif, Inovatif, Kreatif, Efektif, Menyenangkan, Gembira dan Berbobot. Jakarta : Prestasi Pustaka, 2011.

Ma'mur Asmani, Jamal, 7 Tips Aplikasi PAKEM ( Pembelajaran Aktif, kreatif Efektif dan Menyenangkan), Yogyakrta : DIVA Press, 2011.

Sanjaya, Wina. Strategi Pembelajaran, Berorientasi Standar Proses Pendidikan. Jakarta: Kencana Prenada Media Group, 2007.

Silberman, Melvin L. Active Learning.Bandung: Nusamedia, 2011.

Siregar, Eveline \& Hartini Nara.Teori Belajar dan Pembelajaran.Bogor:Ghalia Indonesia, 2010 . 